\title{
Genomic imprinting of Xist by maternal H3K27me3
}

\author{
Azusa Inoue,,$^{1,2,3}$ Lan Jiang, ${ }^{1,2,3}$ Falong Lu, ${ }^{1,2,3,6}$ \\ and Yi Zhang ${ }^{1,2,3,4,5}$
}

\begin{abstract}
${ }^{1}$ Howard Hughes Medical Institute, Boston Children's Hospital, Boston, Massachusetts 02115, USA ${ }^{2}$ Program in Cellular and Molecular Medicine, Boston Children's Hospital, Boston, Massachusetts 02115, USA; ${ }^{3}$ Division of Hematology/Oncology, Department of Pediatrics, Boston Children's Hospital, Boston, Massachusetts 02115, USA; ${ }^{4}$ Department of Genetics, Harvard Medical School, Boston, Massachusetts 02115, USA; ${ }^{5}$ Harvard Stem Cell Institute, Boston, Massachusetts 02115, USA
\end{abstract}

Maternal imprinting at the Xist gene is essential to achieve paternal allele-specific imprinted $X$-chromosome inactivation (XCI) in female mammals. However, the mechanism underlying Xist imprinting is unclear. Here we show that the Xist locus is coated with a broad H3K27me3 domain that is established during oocyte growth and persists through preimplantation development in mice. Loss of maternal H3K27me3 induces maternal Xist expression and maternal XCI in preimplantation embryos. Our study thus identifies maternal H3K27me3 as the imprinting mark of Xist.

Supplemental material is available for this article.

Received July 1, 2017; revised version accepted

September 28, 2017.

In females of certain therian mammals, including rodents, one of the two X chromosomes is inactivated to achieve gene dosage compensation (Augui et al. 2011; Lee and Bartolomei 2013). During development, X-chromosome inactivation $(\mathrm{XCI})$ can take place in either an imprinted or a random manner (Augui et al. 2011; Lee and Bartolomei 2013). For imprinted XCI, the paternal X chromosome $(\mathrm{Xp})$ is selectively inactivated during preimplantation development (Okamoto et al. 2005). Although imprinted $\mathrm{XCI}$ is maintained in the extraembryonic cell lineage, it is lost in the pre-epiblast cell lineage of late blastocysts (Takagi and Sasaki 1975). At the peri-implantation stage, epiblast cells undergo random XCI, resulting in the silencing of either the Xp or maternal X chromosome (Xm) (Lyon 1961). Previous studies have demonstrated a critical role of Xist, an X-linked long noncoding RNA, in both imprinted and random XCI. The Xist RNA participates in $\mathrm{XCI}$ by coating and inactivating the $\mathrm{X}$ chromosome in cis (Penny et al. 1996; Marahrens et al. 1997, 1998; Borensztein et al. 2017).

[Keywords: H3K27me3; X-chromosome inactivation; genomic imprinting; mouse early development]

${ }^{6}$ Present address: State Key Laboratory of Molecular Developmental Biology, Institute of Genetics and Developmental Biology, Chinese Academy of Sciences, Beijing 100101, China.

Corresponding authors: yzhang@genetics.med.harvard.edu, azusa.inoue@ riken.jp

Article is online at http://www.genesdev.org/cgi/doi/10.1101/gad.304113. 117.
To selectively silence the Xp during preimplantation development, Xist is imprinted in the Xm with a longsought-after but yet-to-be-identified mechanism. Previous studies using nuclear transfer approaches have suggested that genomic imprinting of Xist is established during oogenesis (Tada et al. 2000; Oikawa et al. 2014). However, analyses of DNA methyltransferase maternal knockout embryos revealed that oocyte DNA methylation is dispensable for Xist imprinting (Chiba et al. 2008). A recent study demonstrated that overexpression of an H3K9me3 demethylase, $K d m 4 b$, in parthenogenetic (PG) embryos partially derepresses Xist (Fukuda et al. 2014), suggesting the involvement of H3K9me3 in imprinted Xist silencing. However, the fact that PG embryos undergo nonphysiological Xist derepression of a single maternal allele (Nesterova et al. 2001) raises the question of whether the derepression effect observed in the H3K9me3-depleted PG embryos is physiologically relevant. Our recent discovery that maternal H3K $27 \mathrm{me} 3$ serves as an imprinting mark for DNA methylation-independent autosomal gene imprinting (Inoue et al. 2017) prompted us to ask whether it is also responsible for Xist imprinting.

\section{Results and Discussion}

\section{H3K9me3 is dispensable for Xist silencing} in biparental embryos

To determine whether $K d m 4 b$-mediated loss of H3K9me3 can induce Xist derepression in biparental embryos, we injected $K d m 4 b$ mRNA into in vitro fertilization-derived embryos. Immunostaining analysis confirmed that $K d m 4 b$ mRNA injection effectively depleted $\mathrm{H} 3 \mathrm{~K} 9 \mathrm{me} 3$ in zygotes in a concentration-dependent manner (Fig. 1A). To assess Xist RNA expression, we performed RNA fluorescent in situ hybridization (FISH) analysis in four-cell embryos. To distinguish between male and female embryos, we simultaneously labeled X chromosomes by DNA FISH using a probe specific for the Rnf12 locus (Fukuda et al. 2015). As such, each blastomere of the male or female embryos should have one or two DNA FISH signals, respectively. The "no injection" control male embryos showed no Xist RNA signal, and the majority of female embryos showed one RNA cloud or spot signal (Fig. 1B-D). Similarly, Kdm $4 b$-injected embryos did not induce maternal Xist expression in either male or female embryos (Fig. 1B-D), indicating that H3K9me3 does not play a major role in maternal Xist silencing under physiological biparental conditions.

\section{Maternal H3K27me3 coats Xist in oocytes and preimplantation embryos}

Since maternal H3K27me3 can function as an imprinting mark (Inoue et al. 2017), we examined its potential

(C) 2017 Inoue et al. This article is distributed exclusively by Cold Spring Harbor Laboratory Press for the first six months after the full-issue publication date (see http://genesdev.cshlp.org/site/misc/terms.xhtml). After six months, it is available under a Creative Commons License (Attribution-NonCommercial 4.0 International), as described at http://creativecommons.org/licenses/by-nc/4.0/. 
A
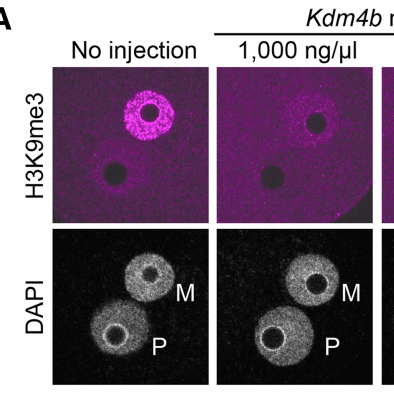

B

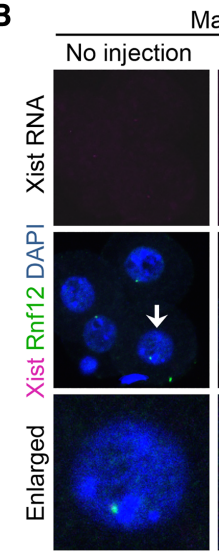

C No injection

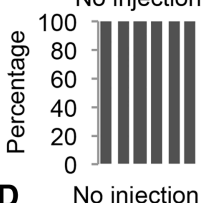

D No injection

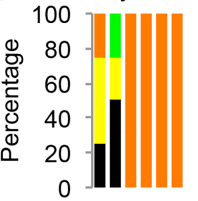

Male
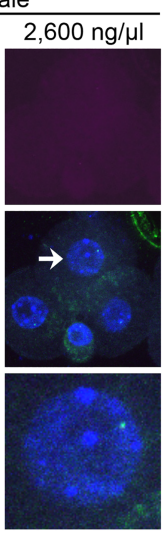

$1,000 \mathrm{ng} / \mu \mathrm{l}$

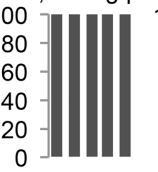

$1,000 \mathrm{ng} / \mu \mathrm{l}$

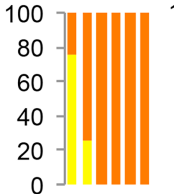

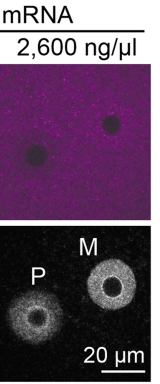
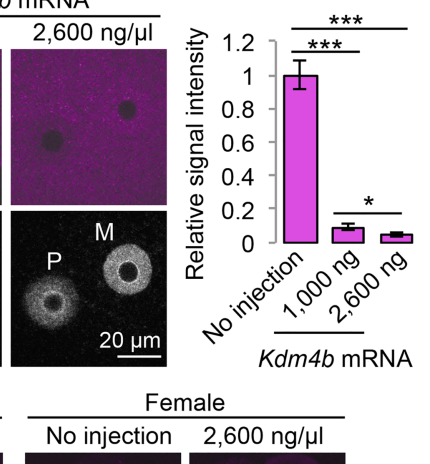

Female

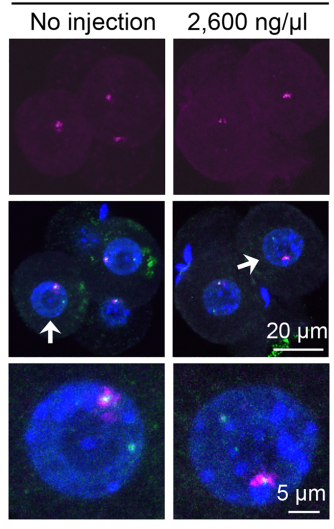

$2,600 \mathrm{ng} / \mu \mathrm{l}$

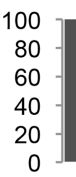

Figure 1. Ectopic removal of $\mathrm{H} 3 \mathrm{~K} 9 \mathrm{me} 3$ does not induce maternal Xist expression. (A) Representative images of zygotes stained with anti-H3K9me3 antibody. (M) Maternal pronucleus; (P) paternal pronucleus. The bar graph shows relative H3K9me3 signal intensity of the maternal pronuclei. The average signal intensity of noninjected zygotes was set as 1.0. The total numbers of embryos examined were eight (no injection), nine (1000 ng/ $\mathrm{LL} \mathrm{Kdm} 4 \mathrm{~b}$ ), and nine (2600 $\mathrm{ng} / \mathrm{\mu L} \mathrm{Kdm} 4 b)$. Error bars indicate SE. $(* *) P<0.001 ;(*) P<0.05$, two-tailed Student's $t$-test. $(B)$ Representative images of Xist RNA FISH (magenta) in $K d m 4 b$-injected four-cell embryos. The gender of each embryo was assessed by simultaneous DNA FISH against the $R n f 12$ locus (green). Arrows indicate the blastomeres enlarged in the bottom panels. $(C, D)$ The ratio of blastomeres that show the indicated number of Xist RNA clouds and spots in male $(C)$ and female $(D)$ embryos. Each bar represents an individual embryo. The numbers of

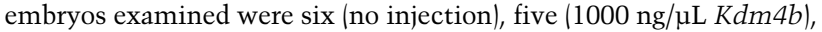
and 12 (2600 ng/ $\mathrm{LL} \mathrm{Kdm4b)} \mathrm{males} \mathrm{and} \mathrm{six} \mathrm{(no} \mathrm{injection),} \mathrm{six} \mathrm{(1000} \mathrm{ng/}$ $\mu \mathrm{L} K d m 4 b)$, and eight (2600 ng/ $\mathrm{LL} K d m 4 b)$ females.

involvement in Xist imprinting. Analysis of H3K27me3 ChIP-seq (chromatin immunoprecipitation [ChIP] combined with high-throughput sequencing) data sets (Zheng et al. 2016) revealed that Xist is coated with a broad H3K27me3 domain, which spans $\sim 450 \mathrm{~kb}$ in mature oocytes and is established during oocyte growth (Fig. 2A). Analyses of the oocyte DNase I sequencing (DNase I-

seq) (Inoue et al. 2017) and DNA methylome (Kobayashi et al. 2012) data sets revealed that this entire H3K27me3 domain exhibits low chromatin accessibility and low DNA methylation (Fig. 2A), suggesting formation of a heterochromatin domain independent of DNA methylation. Analyses of the ChIP-seq data sets of post-fertilization embryos (Zheng et al. 2016) revealed that the maternal H3K27me3 domain is maintained throughout preimplantation development but lost in the embryonic day 6.5 (E6.5) epiblast (Fig. 2B). Notably, the upstream $~ 200-\mathrm{kb}$ region, which spans Xist to Zcchc13 but does not include the Tsix promoter, maintains the maternal allele bias of H3K27me3 enrichment in blastocyst embryos (Fig. $2 \mathrm{C})$. These data support a potential role of maternal H3K27me3 in maternal Xist silencing.

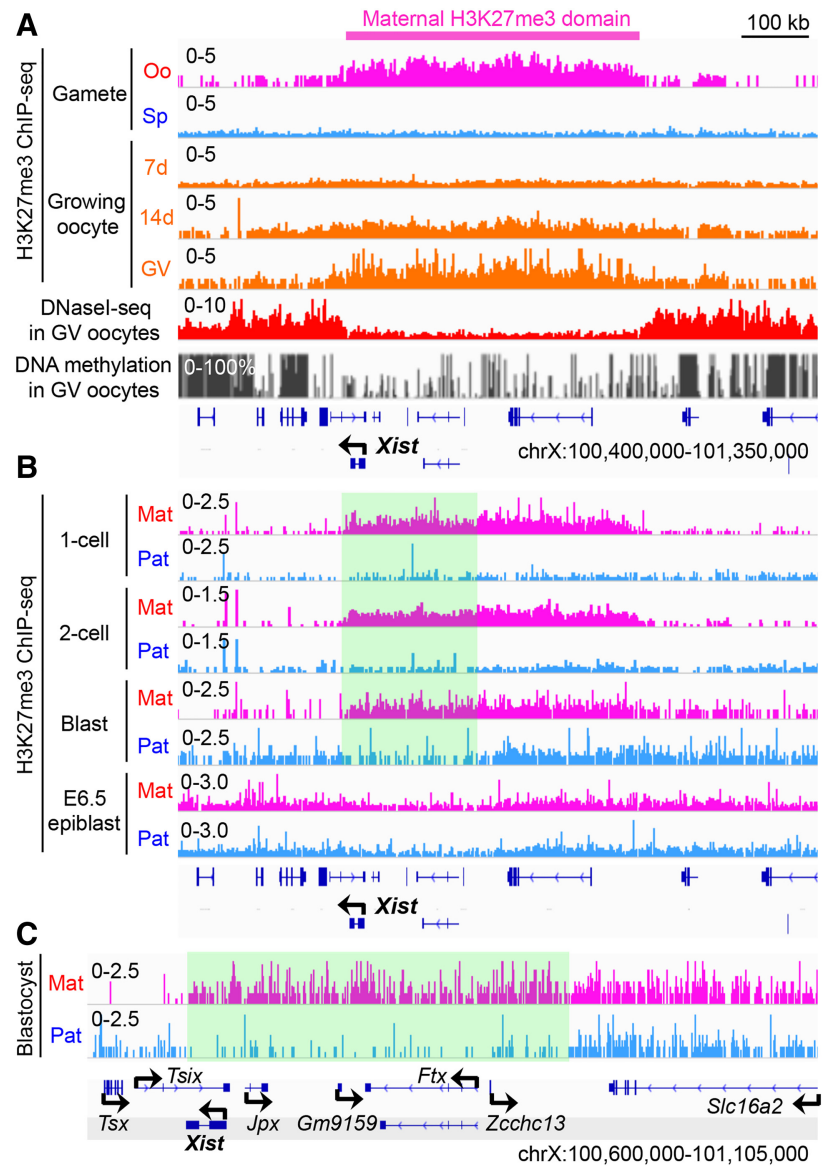

Figure 2. Maternal H3K27me3 coats Xist in oocytes and preimplantation embryos. $(A)$ Genome browser view of H3K27me3 ChIP-seq (Zheng et al. 2016), DNase I-seq (Inoue et al. 2017), and DNA methylation levels (Kobayashi et al. 2012) at the Xist locus. (Oo) MII oocyte; (Sp) sperm; (7 d) growing oocytes collected from 7-d-old females; (14 d) growing oocytes collected from 14-d-old females; (GV) fully grown GV stage oocytes. (B) Genome browser view of allelic H3K27me3 in one-cell, two-cell, and blastocyst embryos and E6.5 epiblast at the Xist locus. The highlighted square indicates a computationally determined region where the maternal allele bias of H3K27me3 enrichment is retained in blastocyst embryos. (Mat) Maternal allele; (Pat) paternal allele. The H3K27me3 ChIP-seq data sets were from Zheng et al. (2016). (C) A higher-resolution view of the Xist locus in blastocyst embryos. The maternal allele-biased $\mathrm{H} 3 \mathrm{~K} 27 \mathrm{me} 3$ domain is highlighted. 


\section{Maternal H3K27me3 is responsible for maternal Xist silencing}

To examine whether $\mathrm{H} 3 \mathrm{~K} 27 \mathrm{me} 3$ is responsible for maternal Xist silencing, we depleted H3K27me3 in zygotes by injecting mRNA coding an H3K27me3-specific demethylase, $K d m 6 b$ (Fig. 3A). As a negative control, we prepared zygotes injected with its catalytic mutant, $K d m 6 b^{M U T}$, harboring a point mutation at the catalytic domain (Fig. $3 \mathrm{~A}$; Inoue et al. 2017). Despite the transient expression of the exogenous Kdm6b, the H3K27me3 level in $K d m 6 b^{W T}$ embryos was significantly lower than that of $K d m 6 b^{M U T}$ embryos at the four-cell and morula stages (Supplemental Fig. S1A,B).

To confirm that $\mathrm{H} 3 \mathrm{~K} 27 \mathrm{me} 3$ is lost at the Xist locus in $K d m 6 b^{W T}$-injected embryos, we performed ultralow input native ChIP-seq (ULI-NChIP) analysis (Brind'Amour et al. 2015), which worked efficiently using 500-2000 mouse embryonic stem cells (Supplemental Fig. S2A). We then performed H3K27me3 ULI-NChIP using 2000 blastomeres from $K d m 6 b^{W T}$ - or $K d m 6 b^{M U T}$-injected morula embryos and validated the data quality by comparing $K d m b b^{M U T}$-injected embryos with a public morula embryo data set (Supplemental Fig. S2B-D; Liu et al. 2016). The number of H3K 27 me 3 peaks in $K d m 6 b^{W T}$-injected embryos was much smaller than that of $K d m 6 b^{M U T}$-injected embryos (Supplemental Fig. S2E). Importantly, the Xist locus exhibits a marked decrease of H3K27me3 enrichment throughout the entire domain in $K d m 6 b^{W T}$ embryos (Supplemental Fig. S2F). Further- more, analysis of single-nucleotide polymorphism (SNP) information revealed that the maternal H3K27me3 domain is lost in $K d m 6 b^{W T}$ embryos (Fig. 3B).

We then asked whether maternal Xist is depressed in $K d m b b^{W T}$-injected four-cell embryos. RNA/DNA FISH analysis revealed that the majority of $K d m 6 b^{W T}$-injected males showed one Xist RNA cloud or spot, while all of the $K d m 6 b^{M U T}$-injected males showed no signal (Fig. $3 \mathrm{C}, \mathrm{D})$. Furthermore, the majority of $K d m 6 b^{W T}$-injected females showed two Xist RNA clouds or/and spots, while most of the $K d m 6 b^{M U T}$-injected females showed one cloud (Fig. 3C,E). These results demonstrate that loss of maternal H3K27me3 at the Xist locus induces maternal $X$ ist derepression at the four-cell stage.

\section{Loss of H3K27me3 induces maternal XCI}

To examine whether maternal Xist expression continues until the morula stage (Fig. 4A), we performed RNA/ DNA FISH analysis. Strikingly, the majority of $K d m 6 b^{W T}$-injected male and female embryos showed one and two RNA clouds, respectively, while most of the $K d m 6 b^{M U T}$-injected male and female embryos showed none and one RNA cloud, respectively (Fig. 4B-D), indicating that the reactivated Xist is persistent. Although Xist can be up-regulated by $R n f 12$ overexpression (Tan et al. 2016), RT-qPCR analysis found no evidence of $R n f 12$ upregulation in $K d m b b^{W T}$-injected embryos (Supplemental Fig. S3), excluding the possibility that $K d m 6 b^{W T}$-mediated Xist depression is due to Rnf12 overexpression.
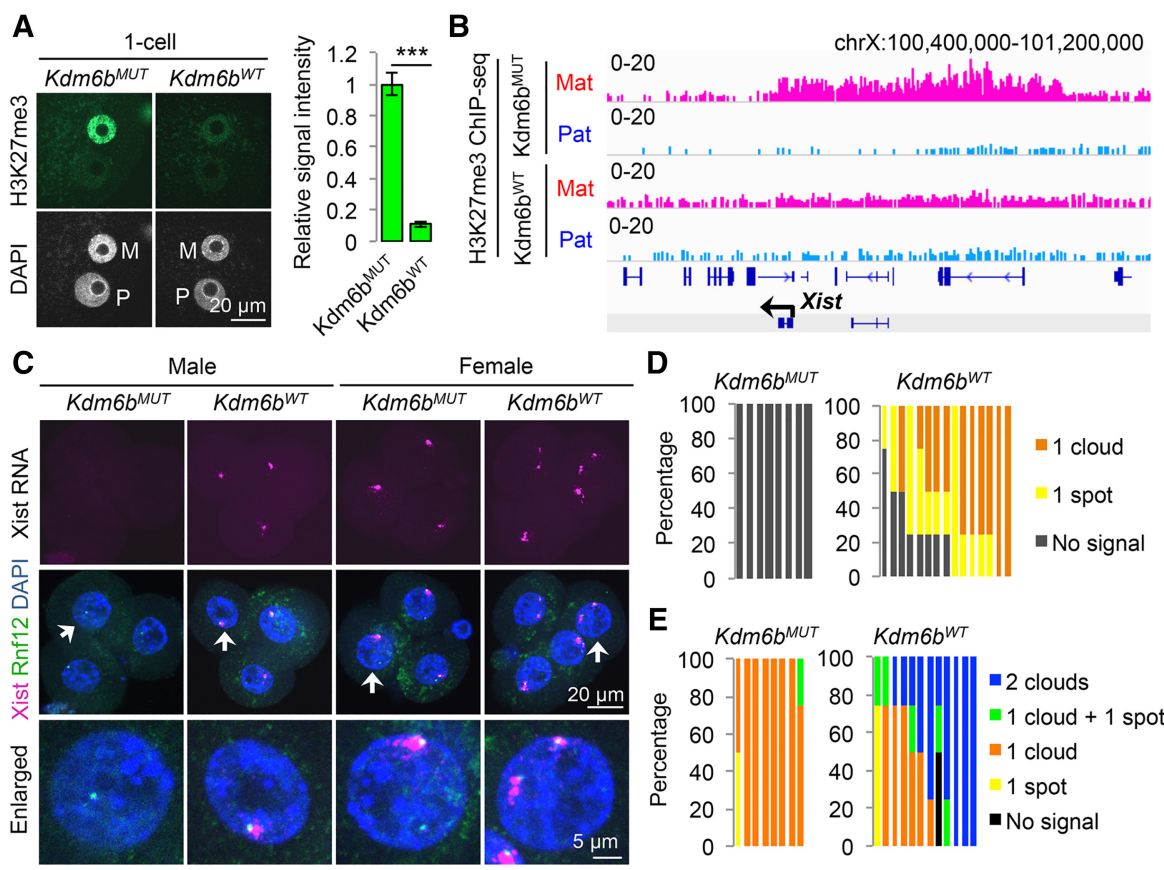

Figure 3. Loss of H3K27me3 induces maternal Xist expression. (A) Representative images of zygotes stained with anti-H3K27me3 antibody. (M) Maternal pronucleus, (P) paternal pronucleus. The bar graph indicates the relative H3K27me3 signal intensity of maternal pronuclei. The average signal of $K d m 6 b^{M U T}$-injected zygotes was set as 1.0 . The total numbers of embryos examined were $15\left(K d m 6 b^{M U T}\right)$ and $13\left(K d m 6 b^{W T}\right)$. Error bars indicate SE. $(* * *) P<0.001$, two-tailed Student's $t$-test. $(B)$ Genome browser view of the Xist locus showing loss of maternal H3K27me3 ChIP-seq signal in $K d m 6 b^{W T}$-injected morula embryos. (Mat) Maternal allele; (Pat) paternal allele. (C) Representative images of Xist RNA FISH (magenta) in $K d m 6 b$-injected four-cell embryos. The gender of each embryo was assessed by simultaneous DNA FISH against the Rnf 12 locus (green). (D,E) The ratio of blastomeres showing the indicated number of Xist RNA clouds and spots in male $(D)$ and female $(E)$ four-cell embryos. Each bar represents an individual embryo. The numbers of embryos examined were eight $\left(K d m 6 b^{M U T}\right)$ and $15\left(K d m 6 b^{W T}\right)$ for males and eight $\left(K d m 6 b^{M U T}\right)$ and 12 $\left(K d m 6^{W T}\right)$ for females. 


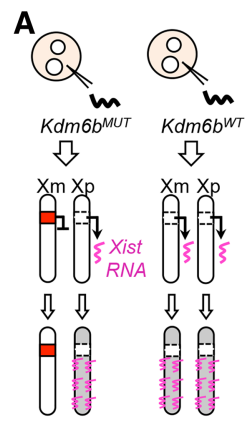

B

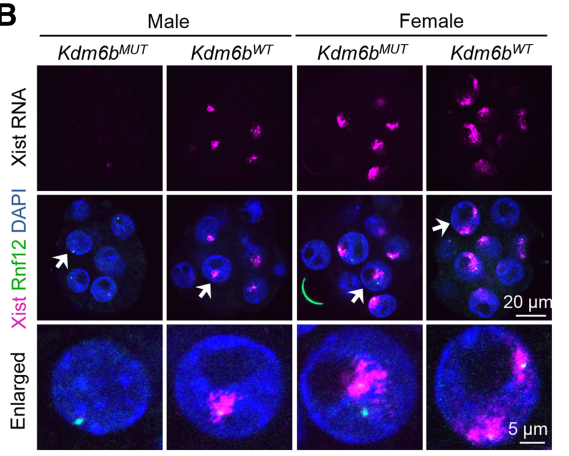

C

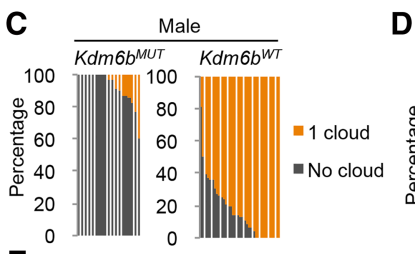

D

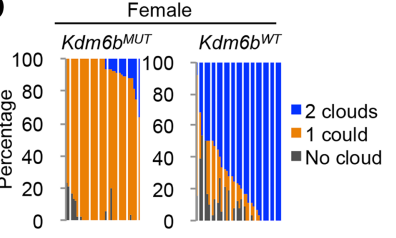

E
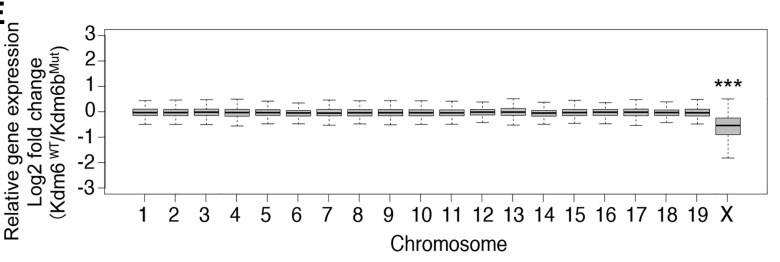

Figure 4. Loss of $\mathrm{H} 3 \mathrm{~K} 27 \mathrm{me} 3$ induces maternal XCI. $(A)$ Illustration depicting maternal XCI caused by $K d m 6^{W T}$-mediated maternal Xist expression. (B) Representative images of Xist RNA FISH (magenta) in $K d m b b$-injected morula embryos. The gender of each embryo was assessed by simultaneous DNA FISH against the Rnf12 locus (green). $(C, D)$ The ratio of blastomeres showing the indicated number of Xist RNA clouds in male $(C)$ and female $(D)$ morula embryos. Each bar represents an individual embryo. The numbers of embryos examined were $19\left(K d m 6 b^{M U T}\right)$ and $35\left(K d m 6 b^{W T}\right)$ for males and 34 $\left(K d m 6 b^{M U T}\right)$ and $35\left(K d m 6 b^{W T}\right)$ for females. $(E)$ Box plot showing the relative expression of genes on individual maternal chromosomes between $K d m 6 b^{M U T}$. and $K d m 6 b^{W T}$-injected blastocysts. Genes with enough SNP reads (SNP reads > 10, RPM [reads per million] > 0.5 were analyzed. The middle lines in the boxes represent the medians. Box edges and whiskers indicate the 25th/75th and 2.5th/ 97.5th percentiles, respectively. $\left(^{* * *}\right) P<0.001$, Mann-Whitney-Wilcoxon test.

To determine whether maternal Xist expression leads to maternal XCI (Fig. 4A), we preformed RNA sequencing (RNA-seq) analysis on early blastocyst stage hybrid mouse embryos with biological duplicates (Supplemental Fig. S4A; Supplemental Table S1). Analysis of SNP information allowed us to examine Xm-linked genes, which revealed that the expression level of Xm-linked genes, but not those of autosomal genes, was significantly down-regulated in $K d m 6 b^{W T}$-injected embryos (Fig. 4E). Consistently, the maternal allele expression bias [Mat/ (Mat + Pat)] of X-linked genes was significantly compromised in $K d m 6 b^{W T}$-injected embryos, although it was still $>50 \%$ (Supplemental Fig. S4B). These data demonstrate that maternal XCI occurs at a level milder than paternal XCI in $K d m b b^{W T}$-injected embryos. A closer examination of individual X-linked genes confirmed that most genes were down-regulated in $K d m 6 b^{W T}$-injected embryos (Supplemental Fig. S4C), while genes known to escape imprinted XCI (Borensztein et al. 2017) were unchanged (Supplemental Fig. S4D), suggesting that $K d m 6 b$-mediated maternal XCI could recapitulate physiological XCI.

Taken together, our data provide evidence that H3K27me3 serves as the imprinting mark of Xist. The domain-based regulation of maternal H3K27me3 at the $X i s t$ locus is an attractive observation and raises important questions. For example, how are the boundaries of the H3K27me3 domain defined during oogenesis? How does the first half $(\sim 200 \mathrm{~kb})$ of the domain, spanning $X$ ist and Zcchc13, maintain the maternal allele-specific H3K27me3 enrichment in blastocyst embryos? Notably, this $\sim 200$-kb region appears to form a topological association domain (Giorgetti et al. 2014), implicating potential involvement of a protein such as CTCF in regulating chromatin boundaries. Interestingly, this domain highly overlaps transgenes whose insertion into an autosome recapitulated imprinted XCI (Okamoto et al. 2005). This raises a possibility that a core element attracting Polycomb group complexes might exist in the region and contribute to imprinting establishment during oogenesis. Further studies are needed to answer these questions. Our study thus not only identifies Xist as a new member of H3K27me3-dependent imprinted genes (Inoue et al. 2017) but also demonstrates the biological significance of H3K27me3-dependent genomic imprinting in safeguarding the Xm from XCI.

\section{Materials and methods \\ Collection of mouse oocytes}

All animal studies were performed in accordance with guidelines of the Institutional Animal Care and Use Committee at Harvard Medical School. The procedures of oocyte collection and in vitro fertilization were described previously (Inoue et al. 2017). The hybrid embryos used for SNP analysis in this study were obtained by in vitro fertilization of B6D2F1/J (BDF1) oocytes and PWK sperm (Jackson Laboratory, 003715).

\section{$m R N A$ preparation and injection}

The construction and preparation of $K d m 6 b \mathrm{mRNA}$ and microinjection into fertilized oocytes were described previously (Inoue et al. 2017). The $K d m 4 b$ construct was generated by cloning its cDNA amplicon into the pcDNA3.1-Flag-poly(A)83 plasmid. mRNA was synthesized with mMESSAGE mMACHINE T7 Ultra kit (Life technologies), purified by lithium chloride precipitation, and dissolved with nuclease-free water. The concentrations of injected mRNA of $K d m 6 b^{W T}$ and $K d m 6 b^{M U T}$ were 1800 $\mathrm{ng} / \mu \mathrm{L}$, and those of $K d m 4 b$ were 1000 or $2600 \mathrm{ng} / \mu \mathrm{L}$.

\section{Probe for FISH}

A probe for Xist RNA was prepared by using Nick translation reagent kit (Abbott Molecular, 07J00-001) with Cy3-dCTP (GE Healthcare, PA53021). The template DNA was a plasmid coding the full-length mouse Xist gene (Addgene, 26760) (Wutz and Jaenisch 2000). A probe for DNA FISH was prepared using the same kit with Green-dUTP (Abbott Molecular, 02N32-050). The template DNA was a BAC clone containing the Rnf12 locus (RP23-36C20) (Fukuda et al. 2015). The fluorescent probes were ethanol-precipitated with $5 \mu \mathrm{g}$ of Cot-1 DNA (Life technologies), 5 $\mu \mathrm{g}$ of herring sperm DNA (Thermo Fisher Scientific), and $2.5 \mu \mathrm{g}$ of yeast tRNA (Thermo Fisher Scientific, AM7119) and then dissolved with 20 $\mu \mathrm{L}$ of formamide (Thermo Fisher Scientific, 17899). The probes were stored at $4^{\circ} \mathrm{C}$. Before being used, the probes $(0.75 \mu \mathrm{L}$ each $)$ were mixed with 0.75 $\mu \mathrm{L}$ of Cot-1 DNA/formamide and $2.25 \mu \mathrm{L}$ of $4 \times$ SSC/20\% dextran (Millipore S4030). The probe mixtures were heated for $30 \mathrm{~min}$ at $80^{\circ} \mathrm{C}$ and then transferred to a $37^{\circ} \mathrm{C}$ incubator ("preannealed probes"). 
Whole-mount RNA/DNA FISH

Four-cell or morula embryos were fixed at 46 or $78 \mathrm{~h}$ post-fertilization (hpf) in $2 \%$ paraformaldehyde (PFA) in PBS containing $0.5 \%$ Triton X-100 for 20 $\mathrm{min}$ at room temperature. After three washes with $0.1 \%$ BSA/PBS, embryos were treated with $0.1 \mathrm{~N} \mathrm{HCl}$ containing $0.02 \%$ Triton X-100 for $15 \mathrm{~min}$ at $4^{\circ} \mathrm{C}$. After three washes with $0.1 \% \mathrm{BSA} / 2 \times \mathrm{SSC}$, embryos were incubated in a series of $10 \%, 20 \%$, and $50 \%$ formamide $/ 2 \times$ SSC in a glass dish (Electron Microscopy Science, 705430-30) and incubated for $30 \mathrm{~min}$. The samples were covered with mineral oil, heated for $30 \mathrm{~min}$ at $80^{\circ} \mathrm{C}$, and then incubated for $>30 \mathrm{~min}$ at $37^{\circ} \mathrm{C}$. The embryos were then transferred into $4.5 \mu \mathrm{L}$ of "preannealed probes," covered with mineral oil on another glass dish, and incubated for $>24 \mathrm{~h}$ at $37^{\circ} \mathrm{C}$. Embryos were washed with $42^{\circ} \mathrm{C}$ prewarmed $0.1 \% \mathrm{BSA} / 2 \times \mathrm{SSC}$, left in the last drop for $30 \mathrm{~min}$, and mounted on a glass slide in VectaShield with DAPI (Vector Laboratories). Fluorescence was detected under a laser-scanning confocal microscope (Zeiss, LSM800).

\section{Whole-mount immunostaining}

The procedure of immunostaining and quantification was described previously (Inoue et al. 2017).

\section{Identification of the maternal allele-biased H3K27me3 domain}

The BED files, including RPKM (reads per kilobase per million mapped reads) values in 100-base-pair (bp) bins for H3K27me3 ChIP-seq in the inner cell mass (ICM), were from GSE76687 (Zheng et al. 2016). BED files labeled maternal- or paternal-containing RPKM values for two parental alleles, and allelic reads were normalized to total read number. "bedtools makewindows" was used to generate 1-kb bins for the entire $\mathrm{mm} 9$ genome, and the RPKM value for each bin was calculated by "bedtools map." All of the bins were classified to three categories of "no signal," "biallelic," and "maternal-biased" using a signal cutoff of 1 and a fold change cutoff of 4 . A sliding window approach was used to identify domains that were enriched for "maternal-biased" H3K27me3 bins. The criteria used were as follows: Within a window of $20 \mathrm{~kb}$, the minimum number of "maternal-biased" bins was three, and the percentage of "maternal-biased" bins was larger than "biallelic" bins. Overlapped windows were merged by "bedtools merge." A total of 5986 domains was identified in the genome.

\section{ULI-NChIP}

At $78 \mathrm{hpf}, \sim 110$ morula embryos per group were briefly treated with acid Tyrode's solution (Sigma-Aldrich) to remove zona pellucida, washed with $0.2 \% \mathrm{BSA} / \mathrm{PBS}$, and transferred to $1.5-\mathrm{mL}$ tubes. The ULI-NChIP was performed using H3K27me3 antibody (Diagenode, C15410069) as described previously (Brind'Amour et al. 2015) with the following modifications. First, we used Beckman SPRIselect beads (Beckman Coulter) instead of Agencourt Ampure XP beads. Second, the sequencing library was prepared using NEBNext Ultra II DNA library preparation kit for Illumina (New England Biolabs). Third, PCR amplification was performed using Kapa Hifi hot start ready mix (Kapa Biosystems). Last, no size selection was performed. For input samples, $10 \%$ volume of the chromatin lysate was taken and used for library construction and sequencing. The quantification and sequencing of the libraries were described previously (Inoue et al. 2017).

\section{Data analysis of ULI-NChIP}

The procedures of alignment and peak calling and the summary of SNPtracked data analyses are described in Supplemental Table S2. For normalization between $K d m 6 b^{M U T}$ and $K d m 6 b^{W T}$ samples, we used a strategy similar to MAnorm (Shao et al. 2012). First, we identified the common peaks between the $K d m 6 b^{M U T}$ and $K d m 6 b^{W T}$ samples. Next, all samples were normalized to the highest coverage samples based on the RPKM value for each sample within the common peaks. SNP-specific reads were normalized to total uniquely mapped reads per library and further normalized to the highest-coverage allele based on the sum of SNP-specific reads per allele. The procedures of reanalysis of public data sets are described in Supplemental Table S2.

\section{Reverse transcription and real-time PCR analysis}

$K d m 6 b$-injected embryos were collected at $46 \mathrm{hpf}$ (four-cell), $60 \mathrm{hpf}$ (eightcell), and $78 \mathrm{hpf}$ (morula). The procedures of reverse transcription and realtime PCR analysis were described previously (Inoue and Zhang 2014) except for the use of random primers for reverse transcription in this study. Primer sequences used for real-time PCR were as follows: 18S-F (5'-TTG ACGGAAGGGCACCACCAG-3'), 18S-R (5'-GCACCACCACCCACGGA ATCG-3'), Rnf12-F (5'-TTTGTCGCAGGGCAGTCTTA-3'), and Rnf12-R (5'-GTTTGCCCATCACTATTCCAGC-3') (Tan et al. 2016).

\section{RNA-seq and data analysis}

Blastocyst embryos at $96 \mathrm{hpf}$ were treated briefly with acid Tyrode's solution, washed by $0.2 \% \mathrm{BSA} / \mathrm{PBS}$, and stored in PCR tubes at $-80^{\circ} \mathrm{C}$. Forty to 46 embryos per group were pooled and used for RNA-seq. RNA-seq libraries were prepared as described previously (Inoue et al. 2017) with the exception of using Nextera XT DNA library preparation kit (Illumina) following cDNA amplification. The procedure of data analysis is described in Supplemental Table S1.

\section{Statistical analyses}

Statistical analyses were implemented with R (http://www.r-project.org). Pearson's $R$ coefficient was calculated using the "cor" function with default parameters. For Supplemental Figure S4B, Mann-Whitney U-Test was performed with the R function "wilcox.test."

\section{Code availability}

A customized pipeline was used to split the alignment of sequencing data from hybrid embryos to their parental origin based on SNP information. The code is available at https://github.com/lanjiangboston/ UniversalSNPsplit.

\section{Data availability}

ChIP-seq and RNA-seq data sets generated in this study are summarized in Supplemental Table S2 and were deposited at the Gene Expression Omnibus database under accession number GSE103714. The WGBS data set for GV oocytes was downloaded from http://www.nodai-genome.org/mouse. html?lang=en (Kobayashi et al. 2012). H3K27me3 ChIP-seq data sets were downloaded from GSE76687 (Zheng et al. 2016). The oocyte DNase I-seq data set was from GSE92605 (Inoue et al. 2017). The BAM file and peak file of ENCODE data were downloaded from https://www. encodeproject.org/files/ENCFF001KDT. Morula embryo H3K27me3 ChIP-seq data sets were from GSE73952 (Liu et al. 2016).

\section{Acknowledgments}

We are grateful to Michihiko Sugimoto (Kumamoto University) and Hirosuke Shiura (Tokyo Medical and Dental University) for technical advice about RNA FISH. We thank Luis Tuesta for critical reading of the manuscript, and Shogo Matoba (RIKEN BioResource Center) and Tatsuya Ohhata (Hamamatsu University School of Medicine) for helpful discussion. This project was supported by the Howard Hughes Medical Institute. L.F. was supported by a Charles A. King Trust Post-doctoral Research Fellowship. Y.Z. is an Investigator of the Howard Hughes Medical Institute. A.I. and Y.Z. conceived the project, A.I. designed and performed the experiments, L.J. analyzed sequencing data sets, F.L. performed RNA-seq, and A. I., L.J., and Y.Z. interpreted the data and wrote the manuscript.

\section{References}

Augui S, Nora EP, Heard E. 2011. Regulation of X-chromosome inactivation by the X-inactivation centre. Nat Genet 12: 429-442.

Borensztein M, Syx L, Ancelin K, Diabangouaya P, Picard C, Liu T, Liang JB, Vassilev I, Galupa R, Servant N, et al. 2017. Xist-dependent 
imprinted $\mathrm{X}$ inactivation and the early developmental consequences of its failure. Nat Struct Mol Biol 24: 226-233.

Brind'Amour J, Liu S, Hudson M, Chen C, Karimi MM, Lorincz MC. 2015. An ultra-low-input native ChIP-seq protocol for genome-wide profiling of rare cell populations. Nat Commun 6: 6033.

Chiba H, Hirasawa R, Kaneda M, Amakawa Y, Li E, Sado T, Sasaki H. 2008. De novoDNA methylation independent establishment of maternal imprint on X chromosome in mouse oocytes. Genesis 46: 768-774.

Fukuda A, Tomikawa J, Miura T, Hata K, Nakabayashi K, Eggan K, Akutsu H, Umezawa A. 2014. The role of maternal-specific H3K9me3 modification in establishing imprinted X-chromosome inactivation and embryogenesis in mice. Nat Commun 5: 5464

Fukuda A, Mitani A, Miyashita T, Umezawa A, Akutsu H. 2015. Chromatin condensation of Xist genomic loci during oogenesis in mice. Development 142: 4049-4055.

Giorgetti L, Galupa R, Nora EP, Piolot T, Lam F, Dekker J, Tiana G, Heard E. 2014. Predictive polymer modeling reveals coupled fluctuations in chromosome conformation and transcription. Cell 157: 950-963.

Inoue A, Zhang Y. 2014. Nucleosome assembly is required for nuclear pore complex assembly in mouse zygotes. Nat Struct Mol Biol 21: 609-616.

Inoue A, Jiang L, Lu F, Suzuki T, Zhang Y. 2017. Maternal H3K27me3 controls DNA methylation-independent genomic imprinting. Nature 547: 419-424.

Kobayashi H, Sakurai T, Imai M, Takahashi N, Fukuda A, Yayoi O, Sato S, Nakabayashi K, Hata K, Sotomaru Y, et al. 2012. Contribution of intragenic DNA methylation in mouse gametic DNA methylomes to establish oocyte-specific heritable marks. PLoS Genet 8: e1002440.

Lee JT, Bartolomei MS. 2013. X-inactivation, imprinting, and long noncoding RNAs in health and disease. Cell 152: 1308-1323.

Liu X, Wang C, Liu W, Li J, Li C, Kou X, Chen J, Zhao Y, Gao H, Wang H, et al. 2016. Distinct features of H3K4me3 and H3K27me3 chromatin domains in pre-implantation embryos. Nature 537: 558-562.

Lyon MF. 1961. Gene action in the X-chromosome of the mouse (Mus musculus L.). Nature 190: 372-373.
Marahrens Y, Panning B, Dausman J, Strauss W, Jaenisch R. 1997. Xist-deficient mice are defective in dosage compensation but not spermatogenesis. Genes Dev 11: 156-166.

Marahrens Y, Loring J, Jaenisch R. 1998. Role of the Xist gene in X chromosome choosing. Cell 92: 657-664.

Nesterova TB, Barton SC, Surani MA, Brockdorff N. 2001. Loss of Xist imprinting in diploid parthenogenetic preimplantation embryos. DeV Biol 235: 343-350.

Oikawa M, Inoue K, Shiura H, Matoba S, Kamimura S, Hirose M, Mekada $\mathrm{K}$, Yoshiki A, Tanaka S, Abe K, et al. 2014. Understanding the X chromosome inactivation cycle in mice. Epigenetics 9: 204-211.

Okamoto I, Arnaud D, Le Baccon P, Otte AP, Disteche CM, Avner P, Heard E. 2005. Evidence for de novo imprinted X-chromosome inactivation independent of meiotic inactivation in mice. Nature 438: 369-373.

Penny GD, Kay GF, Sheardown SA, Rastan S, Brockdorff N. 1996. Requirement for Xist in $\mathrm{X}$ chromosome inactivation. Nature 379: 131-137.

Shao Z, Zhang Y, Yuan GC, Orkin SH, Waxman DJ. 2012. MAnorm: a robust model for quantitative comparison of ChIP-seq data sets. Genome Biol 13: R16.

Tada T, Obata Y, Tada M, Goto Y, Nakatsuji N, Tan S, Kono T, Takagi N 2000. Imprint switching for non-random X-chromosome inactivation during mouse oocyte growth. Development 127: 3101-3105.

Takagi N, Sasaki M. 1975. Preferential inactivation of the paternally derived X chromosome in the extraembryonic membranes of the mouse. Nature 256: 640-642.

Tan K, An L, Miao K, Ren L, Hou Z, Tao L, Zhang Z, Wang X, Xia W, Liu J, et al. 2016. Impaired imprinted $X$ chromosome inactivation is responsible for the skewed sex ratio following in vitro fertilization. Proc Natl Acad Sci 113: 3197-3202.

Wutz A, Jaenisch R. 2000. A shift from reversible to irreversible X inactivation is triggered during ES cell differentiation. Mol Cell 5: 695-705.

Zheng H, Huang B, Zhang B, Xiang Y, Du Z, Xu Q, Li Y, Wang Q, Ma J, Peng $\mathrm{X}$, et al. 2016. Resetting epigenetic memory by reprogramming of histone modifications in mammals. Mol Cell 63: 1066-1079. 


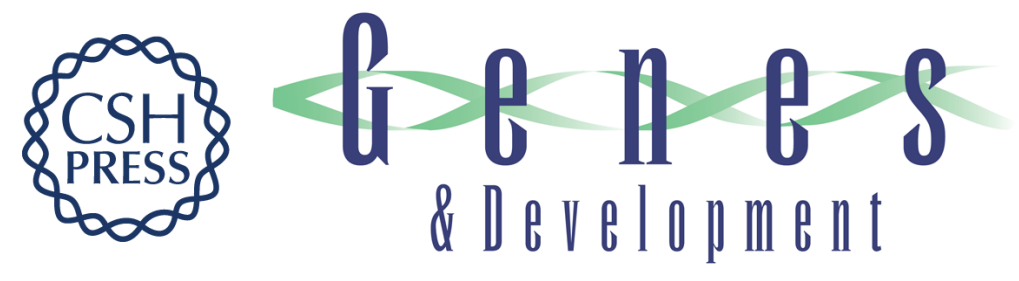

\section{Genomic imprinting of Xist by maternal H3K27me3}

Azusa Inoue, Lan Jiang, Falong Lu, et al.

Genes Dev. 2017, 31:

Access the most recent version at doi:10.1101/gad.304113.117

Supplemental Material

References

Creative Commons License

Email Alerting Service
http://genesdev.cshlp.org/content/suppl/2017/10/31/31.19.1927.DC1

This article cites 25 articles, 4 of which can be accessed free at: http://genesdev.cshlp.org/content/31/19/1927.full.html\#ref-list-1

This article is distributed exclusively by Cold Spring Harbor Laboratory Press for the first six months after the full-issue publication date (see

http://genesdev.cshlp.org/site/misc/terms.xhtml). After six months, it is available under a Creative Commons License (Attribution-NonCommercial 4.0 International), as described at http://creativecommons.org/licenses/by-nc/4.0/.

Receive free email alerts when new articles cite this article - sign up in the box at the top right corner of the article or click here.

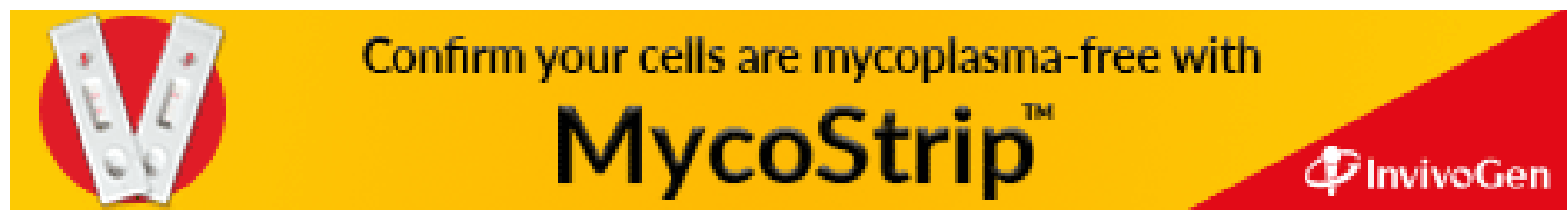

